\title{
Sesamol suppresses cyclooxygenase-2 transcriptional activity in colon cancer cells and modifies intestinal polyp development in $\mathrm{Apc}^{\mathrm{Min} /+}$ mice
}

\author{
Satomi Shimizu, ${ }^{1,2}$ Gen Fujii, ${ }^{1}$ Mami Takahashi, ${ }^{3}$ Ruri Nakanishi, ${ }^{1}$ Masami Komiya, ${ }^{1}$ Misato Shimura, ${ }^{1,4}$ \\ Nobuharu Noma, ${ }^{1,4}$ Wakana Onuma, ${ }^{1,4}$ Masaru Terasaki, ${ }^{5}$ Tomohiro Yano $^{2}$ and Michihiro Mutoh ${ }^{1, *}$
}

\begin{abstract}
'Division of Cancer Prevention Research and ${ }^{3}$ Central Animal Division, National Cancer Center Research Institute, 5-1-1 Tsukiji, Chuo-ku, Tokyo 104-0045, Japan ${ }^{2}$ Faculty of Life Sciences, Toyo University, 1-1-1 Izumino, Itakura-machi, Oga-gun, Gunma 374-0193, Japan

${ }^{4}$ School of Pharmaceutical Sciences, Tokyo University of Science, 2641 Yamazaki, Noda-shi, Chiba 278-8510, Japan

${ }^{5}$ Faculty of Pharmaceutical Sciences, Health Science University of Hokkaido, 1757 Kanazawa, Ishikari-Tobetsu, Hokkaido 061-0293, Japan
\end{abstract}

(Received 11 October, 2013; Accepted 4 December, 2013; Published online 19 February, 2014)

Excessive prostaglandin production by cyclooxygenase-2 in stromal and epithelial cells is a causative factor of colorectal carcinogenesis. Thus, compounds which inhibit cyclooxygenase-2 transcriptional activity in colon epithelial cells could be candidates for anticarcinogenic agents. A cyclooxygenase-2 transcriptional activity in the human colon cancer cell line DLD-1 has been measured using a $\beta$-galactosidase reporter gene system. Using this system, we demonstrated that the decrease in basal cyclooxygenase-2 transcriptional activities at $100 \mu \mathrm{M}$ sesamol, one of the lignans in sesame seeds, was $\mathbf{5 0 \%}$. Other compounds in sesame seeds such as sesamin, sesamolin, ferulic acid, and syringic acid did not exhibit significant suppression of cyclooxygenase-2 transcriptional activity at up to $100 \mu \mathrm{M}$. In a following experiment, 6week-old male Min mice, Apc-deficient mice, were divided into a non-treated and $500 \mathrm{ppm}$ sesamol groups. At the age of 15 weeks, it was found that treatment with sesamol decreased the number of polyps in the middle part of small intestine to $66.1 \%$ of the untreated value. Moreover, sesamol suppressed cyclooxygenase-2 and cytosolic prostaglandin $E_{2}$ synthase mRNA in the polyp parts. The present findings may demonstrate the novel anti-carcinogenetic property of sesamol, and imply that agents that can suppress cyclooxygenase- 2 expression may be useful cancer chemopreventive agents.

Key Words: cyclooxygenase-2, reporter gene assay, sesame, sesamol, Min mice

$\mathrm{T}$ he sesame plant (Sesamun indicum, Linn.) is well known for its edible seeds and oil.(1) Sesame seeds are characterized by the presence of fatty acids (linoleic acid, linolenic acid, oleic acid, palmitic acid and stearic acid), oil-soluble lignans (episesamin, sesamin, sesaminol, sesamol and sesamolin) and other phenol compounds ( $\gamma$-tocophenol, ferulic acid and syringic acid). The nonfat portion of sesame seed is only $1-2 \%$ by wet weight. Recently, multiple biological functions of sesame seeds, such as inhibition of inflammation and carcinogenesis, have been elucidated. In experimental studies, sesamol was shown to inhibit development of spontaneous development of preneoplastic hepatocytic foci in rats. ${ }^{(2)}$ Sesamin reduced the incidence of chemically induced rat mammary gland cancers. ${ }^{(3)}$ Moreover, sesame oil has been reported to inhibit growth of human colon cancer cells in vitro. ${ }^{(4)}$ These effects of sesame seed and its constituents were partly associated with its hydroxyl radical scavenging activity, inhibitory activity of lipid peroxidation and anti-mutageneic activity. ${ }^{(5-7)}$ However, the desirable biological functions have not entirely been elucidated yet.

Recent accumulating evidence has indicated that prostaglandins (PGs) are implicated in colon carcinogenesis. ${ }^{(8)}$ Expression levels of cyclooxygenase-2 (COX-2) are increased in colon carcinoma tissues compared to that of normal colonic mucosa. Therefore, inhibitors against COX-2 have been studied extensively for their ability to suppress colon carcinogenesis. It has been also reported that COX-2 gene knockout causes significant reduction in number and size of intestinal polyps in a mouse model for human familial adenomatous polyposis, Apc-deficient Min mice. ${ }^{(9)}$ Thus, it is likely that agents that can suppress $\mathrm{COX}-2$ expression at the transcriptional level may be equally advantageous.

As reported in previous papers, ${ }^{(10-12)}$ we have constructed a $\beta$ galactosidase reporter gene system to test the effects of compounds on COX-2 transcriptional activity in a human colon cancer cell line, DLD-1 cells. In the present study, effects of five sesame seeds constituents on the transcriptional activity of COX-2 were investigated and one constituent, sesamol, was found to suppress basal COX-2 transcriptional activity. In a further experiment, we investigated the suppressive effect of sesamol on intestinal polyp development and on COX-2 expression levels in Min mice.

\section{Materials and Methods}

Chemicals. Sesamin were obtained from Cayman Chemical, (Ann Arbor, MI), ferulic acid, sesamol and syringic acid were from Sigma-Aldrich Co. (St. Louis, MO). Sesamolin was from Nagara, Ltd. (Gifu, Japan).

Cell culture. DLD-1 cells, a human colon adenocarcinoma cell line, were obtained from the Japanese Collection of Research Bioresources Cell Bank (Osaka, Japan). Construction of DLD-1/ COX-2-B2- $\beta$ Gal-BSD cells has been reported in our previous papers. ${ }^{(13)}$ The cells were maintained in DMEM medium supplemented with $5 \%$ heat-inactivated fetal bovine serum (FBS; Hyclone Laboratories Inc., Logan, UT) and antibiotics $(100 \mu \mathrm{g} / \mathrm{ml}$ streptomycin and $100 \mathrm{U} / \mathrm{ml}$ penicillin) at $37^{\circ} \mathrm{C}$ in $5 \% \mathrm{CO}_{2}$.

Measurements of cell viability. Cell viability in each culture was determined by the 3-(4,5-dimethylthiazol-2-yl)-2,5diphenyltetrazolium bromide (MTT) assay. Cells at a density of $2.0 \times 10^{4}$ cells per well were seeded in 96-well tissue culture plates

*To whom correspondence should be addressed. E-mail: mimutoh@ncc.go.jp 
and treated with sesame constituents for $48 \mathrm{~h}$. After treatment, the cells were further incubated in a medium containing $0.5 \mathrm{mg} / \mathrm{mL}$ of MTT for $1 \mathrm{~h}$. The MTT formazan produced by living cells was dissolved in dimethyl sulfoxide and absorbance at $595 \mathrm{~nm}$ was measured on a microplate Reader (Bio-Rad Laboratories, CA).

Reporter gene assay for COX-2 promoter-dependent transcriptional activity. DLD-1/COX-2-B2- $\beta$ Gal-BSD cells were seeded at a density of $2.0 \times 10^{4}$ cells per 96-well tissue culture plate and precultured for $24 \mathrm{~h}$. After treatment with the test reagents, the total $\beta$-galactosidase activities of the cells in each well were determined by colorimetric assay using $o$-nitrophenyl$\beta$-d-galactopyranoside (ONPG) as described previously. ${ }^{(10,11)}$ The background $\beta$-galactosidase activity of DLD-1 cells was determined in non-treated DLD-1/B2- $\beta$ Gal-BSD cells, and the value was set as 0 . Basal $\beta$-galactosidase activity of non-treated DLD-1/ COX-2-B2- $\beta$ Gal-BSD cells was set as $100 \%$. The percent $\beta$ galactosidase activity of each treatment was calculated from triplicate wells. The viable cell number was assessed by the MTT assay. All assays, including MTT assay, were carried out in triplicate and each experiment repeated at least three times.

Quantitative real-time polymerase chain reaction (PCR) analysis. Total RNA was isolated using TRIzol Reagent (Invitrogen, NY), treated with DNase (Invitrogen, Grand Island, NY) and $1 \mu \mathrm{g}$ aliquots in a final volume of $20 \mu \mathrm{L}$ were used for synthesis of cDNA using a High Capacity cDNA Reverse Transcription Kit (Applied Biosystems). Real-time PCR was carried out using Fast Start Universal SYBR Green Mix (Roche Diagnostics, Mannheim, Germany) according to the manufacturer's instructions. Primers for COX-1 (5'-TGA TGC TCT TCT CCA CGA and 5'-GCA GGA AAT AGC CAC TCA AG), COX-2 (5'-GTG CCA ATT GCT GTA CAA GC and 5'-TAC AGC TCA GTT GAA CGC CT), cPGES (5'-AGT CAT GGC CTA GGT TAA C and 5'TGT GAA TCA TCA TCT GCT CC), EP1 (5'-ACC CTG CAT CCT GAG CAG CAC TGG CCC TCT and 5'-CGA TGG CCA ACA CCA CCA ACA CCA GCA GGG), EP2 (5'-AGG ACT TCG ATG GCA GAG GAG AC and 5'-CAG CCC CTT ACA CTT CTC CAA TG), EP3 (5'-TGA CCT TTG CCT GCA ACC TG and 5'-AGA CAA TGA GAT GGC CTG CC), EP4 (5'-TCC CGC TCG TGG TGC GAG TGT TC and 5'-GAG GTG GTG TCT GCT TGG GTC AG), mPGES-2 (5'-AAG ACA TGT CCC TTC TGC and 5'-CCA AGA TGG GCA CTT TCC) and glyceraldehyde-3-phosphate dehydrogenase (GAPDH) (5'-TGT CAG CAA TGC ATC CTG CA and 5'-TTA CTC CTT GGA GGC CAT GT) were employed. For evaluation of human mRNA levels, indicated primers as shown below were used. Human EP1 (5'-TCT ACC TCC CTG CAG CGG CCA CTG and 5'-GAA GTG GCT GAG GCC GCT GTG CCG GGA), human EP2 (5'-ATG GGC AAT GCC TCC AAT GAC TCC CAG and 5'-CTC CAG GGA ACA ATT TCA AAA T), human EP4 (5'-CCT CCT GAG AAA GAC ACT GCT and 5'-AAG ACA CTC TCT GAG TCC T), and human GAPDH (5'-CCA CCC ATG GCA AAT TCC and 5'-TGG GAT TTC CAT TGA TGA CAA). To assess the specificity of each primer set, amplicons generated from the PCR reaction were analyzed for melting curves.

Western blot analysis. EP1-4 protein levels were analyzed by western blot. DLD-1/COX-2-B2- $\beta$ Gal-BSD cells were seeded at a density of $2 \times 10^{5}$ well in 24 -well plates, and incubated with 50 and $100 \mu \mathrm{M}$ sesamol for 24 and $48 \mathrm{~h}$. After treatment, cells were lysed in $100 \mu \mathrm{l}$ lysis buffer $[0.0625 \mathrm{M}$ Tris- $\mathrm{HCl}$ (pH 6.8), $20 \%$ 2-mercaptoethanol, $10 \%$ glycerol, 5\% sodium dodecyl sulfate]. Samples were separated in $10 \%$ polyacrylamide gel electrophoresis-sodium dodecyl sulfate gels and transferred onto polyvinylidene difluoride membranes (Millipore, MA). Abs against the EP1, EP2, EP4 (Cayman Chemical Co. Ann Arbor, MI) and EP3 (Santa Cruz Biotechnology, Inc., Santa Cruz, CA) was used at a 1:2,000 dilution. Peroxidase-conjugated secondary Abs for anti-rabbit IgG were obtained from GE Healthcare (Buckingham shire, UK). Blots were developed with ECL western blotting detection reagents (GE Healthcare).

Animals. Female $\mathrm{C} 57 \mathrm{BL} / 6-A p c^{\mathrm{Min} /+}$ mice (Min mice) were purchased from The Jackson Laboratory (ME). Mice were housed per plastic cage with sterilized softwood chips as bedding in a barrier-sustained animal room at $24 \pm 2{ }^{\circ} \mathrm{C}$ and $55 \%$ humidity on a $12 \mathrm{~h}$ light/dark cycle. Sesamol was well mixed at a concentration of $500 \mathrm{ppm}$ in AIN-76A powdered basal diet (CLEA Japan, Tokyo, Japan).

Protocol for Animal experiments. Ten female Min mice at 5 weeks of age were given $500 \mathrm{ppm}$ sesamol, for 8 weeks. The animals in each cage were all in the same treatment group. Food and water were available ad libitum. The animals were observed daily for clinical signs and mortality. Body weights and food consumption were measured weekly. The intestinal tract was removed and separated into the small intestine, cecum and colon. The small intestine was divided into the proximal segment $(4 \mathrm{~cm}$ in length) and then the proximal (middle) and distal halves of the remainder. Polyps in the proximal segments were counted and all<smiles></smiles><smiles></smiles><smiles>COc1cc(/C=C/C(=O)O)ccc1O</smiles>

Ferulic acid<smiles>COc1cc(C(=O)O)cc(OC)c1O</smiles>

Syringic acid

Fig. 1. Chemical structures of the five constituents in the sesame seed. (A), sesamol; (B), sesamin; (C), sesamolin; (D), ferulic acid; (E), syringic acid. 
polyps in the proximal segment were picked up under a stereoscopic microscope and the remaining intestinal mucosa (nonpolyp part) was removed by scraping, and then both stored at $-80^{\circ} \mathrm{C}$ for further analysis. Other segments were opened longitudinally and fixed flat between sheets of filter paper in $10 \%$ buffered formalin. The numbers and sizes of polyps and their distributions in the intestine were assessed with a stereoscopic microscope. The experiments were performed according to the "Guidelines for Animal Experiments in the National Cancer Center" and were approved by the Institutional Ethics Review Committee for Animal Experimentation in the National Cancer Center.

Statistical analysis. All the results are expressed as mean \pm SD. values, with statistical analysis using the Student's $t$ test, except for the COX-2 promoter activity investigation and mRNA examination in the human cell line. The Bonferroni $z$ test was used for statistical analyses of the COX-2 promoter activity and of human mRNA levels. Differences were considered to be statistically significant at $p<0.05$.

\section{Results}

Suppression of COX-2 promoter activity in human colon cancer cells by sesamol. Five compounds, shown in Fig. 1, were tested at various concentrations up to $100 \mu \mathrm{M}$ with regard to their effects on COX-2 promoter activity. Remarkable suppression of cell proliferation rates by five compounds was not observed at the concentrations up to $100 \mu \mathrm{M}$ in MTT assay. Among five constituents in the sesame seed, only sesamol significantly suppressed COX-2 prompter activity in a dose-dependent manner. Decrease in COX-2 promoter activities by sesamol at $100 \mu \mathrm{M}$ was $50 \%$ (Fig. 2A). The other four compounds, ferulic acid, sesamin, sesamolin, syringic acid exhibited weak or no suppression of COX-2 promoter activity (Fig. 2B-E).

Suppression of intestinal polyp formation in Min mice by sesamol. Administration of $500 \mathrm{ppm}$ sesamol to Min mice for 8 weeks did not affect body weights, food intake or clinical signs throughout the experimental period. Average daily food intake did not significantly differ among the groups, being 3.9 and $3.5 \mathrm{~g}$ per mouse per day for the 0 and $500 \mathrm{ppm}$ group of Min mice, respectively. In addition, there were no changes observed in any organ weights that might have been attributable to toxicity.

Table 1 summarizes data for the number and distribution of intestinal polyps in the basal diet and sesamol-treated groups. Almost all polyps developed in the small intestine, with only a few in the colon. The total number of polyps tended to be decreased by administration of $500 \mathrm{ppm}$ sesamol to $75 \%$ of the untreated control value. Reduction of polyps was observed in the middle part, and was by $66 \%(p<0.05$ vs $0 \mathrm{ppm})$. In the other parts of small intestine and colon, treatment with sesamol lowered the number of polyps without significant difference.

Fig. 3 shows the size distribution of intestinal polyps in the basal diet and sesamol-treated groups. The maximal number of polyps was observed in the size range between 0.5 and $2.0 \mathrm{~mm}$ in diameter. Administration of sesamol significantly reduced the numbers of polyps sized $<0.5 \mathrm{~mm}$ in diameter.

Decrease of inflammation-related factors mRNA levels in intestinal polyp parts by sesamol. Inflammation-related factors mRNA expressions in intestinal polyp parts and non-polyp parts were investigated (Fig. 4). Real-time PCR revealed that treatment with $500 \mathrm{ppm}$ sesamol for 8 weeks significantly suppressed COX-2, and cPGES, mRNA levels in the intestinal polyp parts to $48 \%(p<0.01)$ and $54 \%(p<0.05)$ of sample value, respec-
A
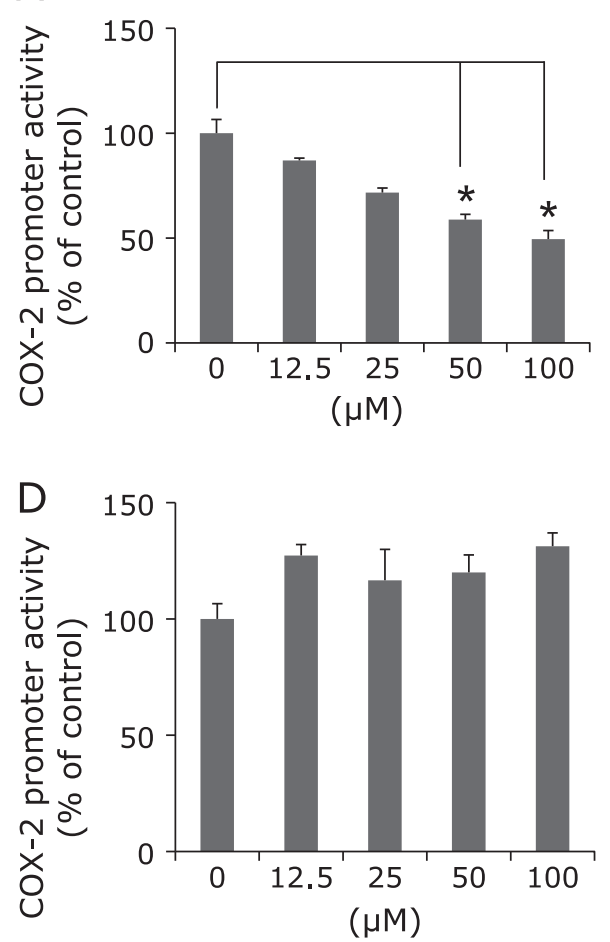

B
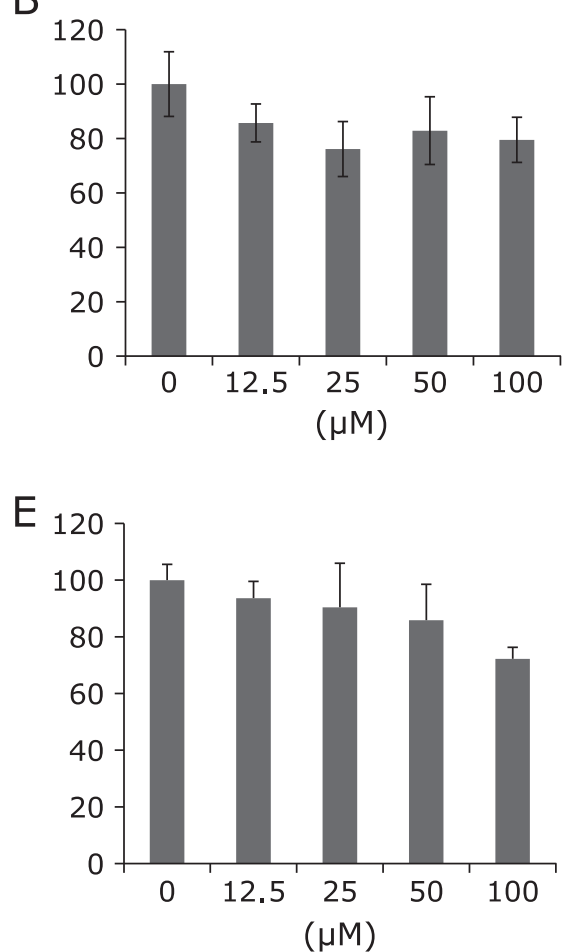

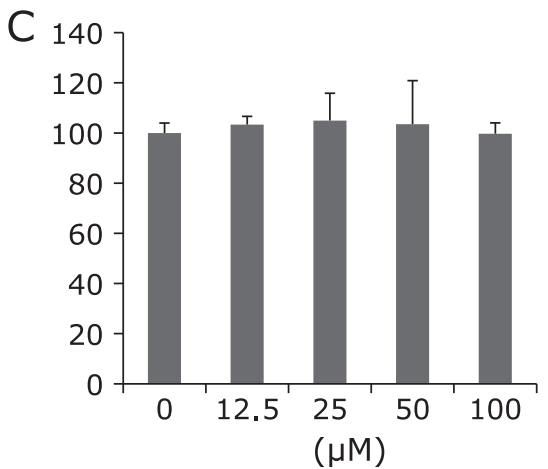

$(\mu \mathrm{M})$

Fig. 2. Effects of treatment with sesame constituents on reporter gene activity in DLD-1/COX-2-B2- $\beta$-gal-BSD cells. DLD-1/COX-2-B2- $\beta$-gal-BSD cells were seeded in 96-well multiwell plates at a density of $2 \times 10^{5}$ cell/well and cultured in medium containing sesame constituents at concentrations up to $100 \mu \mathrm{M}$. After $48 \mathrm{~h}$, the COX-2 promoter activity was evaluated by $\beta$-galactosidase activity and was normalized for viable cell numbers assessed by MTT assay. The columns indicate the values of the mean percentages of triplicate wells of promoter activity of DLD-1/COX-2-B2- $\beta$-gal-BSD cells. The data are representative of more than three independent experiments. Bars indicate the SD. ${ }^{*} p<0.05$. (A), sesamol; (B), sesamin; (C), sesamolin; (D), ferulic acid; (E), syringic acid. COX; cyclooxygenase, CPGES; cytosolic PGES, mPGES; microsomal PGES, PGES; prostaglandin E synthase. 
Table 1. Number of intestinal polyps/mouse in Min mice

\begin{tabular}{ccccccc}
\hline \multirow{2}{*}{ Sesamol $(\mathrm{ppm})$} & \multirow{2}{*}{ No. of mice } & \multicolumn{3}{c}{ Small intestine } & \multirow{2}{*}{ Colon } & \multirow{2}{*}{ Total } \\
\cline { 3 - 6 } & & Proximal & Middle & Distal & & \\
\hline 0 & 9 & $4.9 \pm 4.6$ & $17.1 \pm 5.6$ & $22.1 \pm 11.7$ & $0.7 \pm 1.3$ & $44.8 \pm 15$ \\
500 & 8 & $2.4 \pm 1.5$ & $11.3 \pm 5.6^{*}$ & $19.9 \pm 4.4$ & $0.1 \pm 0.4$ & $33.6 \pm 9.2^{\#}$ \\
\hline
\end{tabular}

Data are mean \pm SD. *Significantly different from the control untreated group at $p<0.01 .{ }^{\#} p=0.087$.

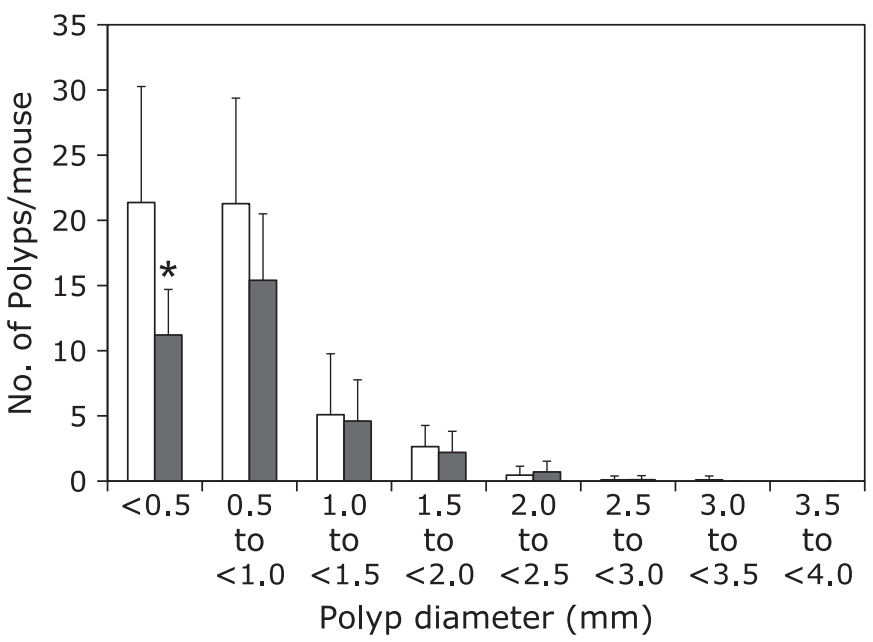

Fig. 3. Effects of sesamol on the size distribution of intestinal polyps in Min mice. Min mice were fed a basal diet (open box) or a containing $500 \mathrm{ppm}$ (black filled box) sesamol for 8 weeks. The number of polyps per mouse in each size class is given as a mean \pm SD. ${ }^{*} p<0.05$.

tively. mPGES2, EP1 and EP2 mRNA levels tended to be reduced in intestinal polyp parts by sesamol. COX-1 and EP4 mRNA expression levels in non-polyp parts and polyp parts of small intestine were not suppressed by sesamol treatment. Only EP3 did not increase its expression levels in the intestinal polyp parts compared to those of mucosa parts, and rather decreased its expression by sesamol treatment in the intestinal polyp parts.

Decrease of prostaglandin $E_{2}$ receptor expression levels in human colon cancer cells by sesamol. To clarify the effects of sesamol on EP1 and EP2 mRNA levels in human cells, we treated DLD-1/COX-2-B2- $\beta$-gal-BSD cells with 50 and $100 \mu \mathrm{M}$ sesamol for $48 \mathrm{~h}$. Sesamol significantly suppressed EP1 and EP2 mRNA levels in a dose-dependent manner (Fig. 5). However, mRNA levels for EP4 were increased and EP3 was not clearly detected (data not shown). We further confirmed the EP14 protein expression levels in the cells with or without sesamol treatment. As shown in Fig. 5D, sesamol down-regulated EP1 and EP2 protein levels in dose- and time-dependent manner. As in the case of EP4, sesamol treatment for $24 \mathrm{~h}$ slightly increased its protein levels, whereas $48 \mathrm{~h}$ treatment decreased EP4 protein levels. EP3 expression levels seem to be very low in these cells, as shown in Fig. 5D.

\section{Discussion}

In the present study, sesamol was found to suppress basal transcriptional activity of the COX-2 gene in human colon cancer DLD-1 cells. Previously, we have reported that mono-benzonic compounds such as resorcinol and resacetophenone suppress COX-2 transcriptional activity, ${ }^{(10,11)}$ but their inhibitory activities are almost 5-times less than that of sesamol. Thus, sesamol may have a notable potential to suppress COX-2 expression for a natural compound.
The underlying mechanism of suppression of COX-2 transcriptional activity by sesamol is not clear. Protein-tyrosine kinases (PTKs), including the epidermal growth factor receptor, are well known to be involved in the induction of COX-2 expression. ${ }^{(14,15)}$ Signals from activated PTKs are transduced to the downstream transcription factor NF- $\kappa \mathrm{B}$, mainly by the Ras and mitogenactivated protein kinase pathways. It is also known that activation of NF- $\kappa \mathrm{B}$ has been reported to play an important role in the regulation of COX-2 expression. However, our preliminary experiment that aimed to evaluate the effects of sesamol on NF- $\kappa B$ transcriptional activity failed to show its reduction at concentrations up to $100 \mu \mathrm{M}$ in human colon cancer cells (data not shown). Further studies are needed to elucidate the molecular mechanisms responsible for the inhibition of COX-2 transcriptional activity by sesamol.

We next aimed to show the suppressive potential of sesamol on intestinal polyp development in Min mice. Administration of $500 \mathrm{ppm}$ sesamol tended to reduce the total number of intestinal polyps development compared to that of the untreated group. Further analysis revealed that treatment with sesamol decreased the number of polyps in the middle part of the small intestine. It has been reported that indomethacin, a COX inhibitor, and nimesulide, a COX-2 selective inhibitor, mainly reduce the number of polyps in the middle to distal part of the small intestine. ${ }^{(16,17)}$ Thus, sesamol with a COX-2 suppressive function has a similar inhibitory potential for polyp development. For instance, LPL inducers such as NO-1886 or PPAR ligands effectively reduce the number of polyps in the proximal part of the small intestine. ${ }^{(18,19)}$

In the polyp parts of Min mice, it was confirmed that sesamol could suppress expression levels of COX-2 mRNA. In addition, cPGES mRNA was reduced by sesamol treatment, and this is the first report that suggests suppressive effects of sesamol on cPGES as far as we know. Moreover, a tendency to suppression was observed in the expression levels of PGE2 receptor subtypes EP1 and EP2 in the polyp parts of Min mice. Using $\mathrm{PGE}_{2}$ receptor subtype-knockout mice, the roles of these receptors in colon carcinogenesis have been investigated. ${ }^{(20-23)}$ These observations suggest that EP1, EP2 and EP4 are promotive receptors in colorectal carcinogenesis, and EP3 plays suppressive roles. EP1 signals transmitted by increased intracellular $\mathrm{Ca}^{2+}$ concentrations activate protein kinase $\mathrm{C}$ (PKC). However, the actual signal transduction mechanisms are not known in detail. ${ }^{(24,25)}$ Stimulation of EP2 and EP4 receptors in both cases involves coupling with stimulatory $\mathrm{G}$ protein, leading to activation of adenylate cyclase. As a result, increased cAMP levels activate cAMP-dependent protein kinase (PKA) and increase a transcriptional factor that binds to cAMP-responsive element, that plays a role in cell growth and cell survival. Thus, it may be worthwhile to develop functional inhibitors or specific suppressors for EP1, EP2 and EP4. However, it is regrettable that there are a few inhibitors for $\mathrm{PGE}_{2}$ receptor subtypes. To add to the novel potential of sesamol, we confirmed the effect of sesamol on human EP1 and EP2 mRNA levels. We found suppression of EP1 and EP2 mRNA levels by sesamol treatment. Down-regulation of EP1 and EP2 protein was also confirmed. These data imply a double suppressive potential exists in sesamol regarding cell growth function of PGE2. Suppression of COX-2 may reduce production of growth lipid mediator $\mathrm{PGE}_{2}$, and down regulation of $\mathrm{PGE}_{2}$ receptors such as 

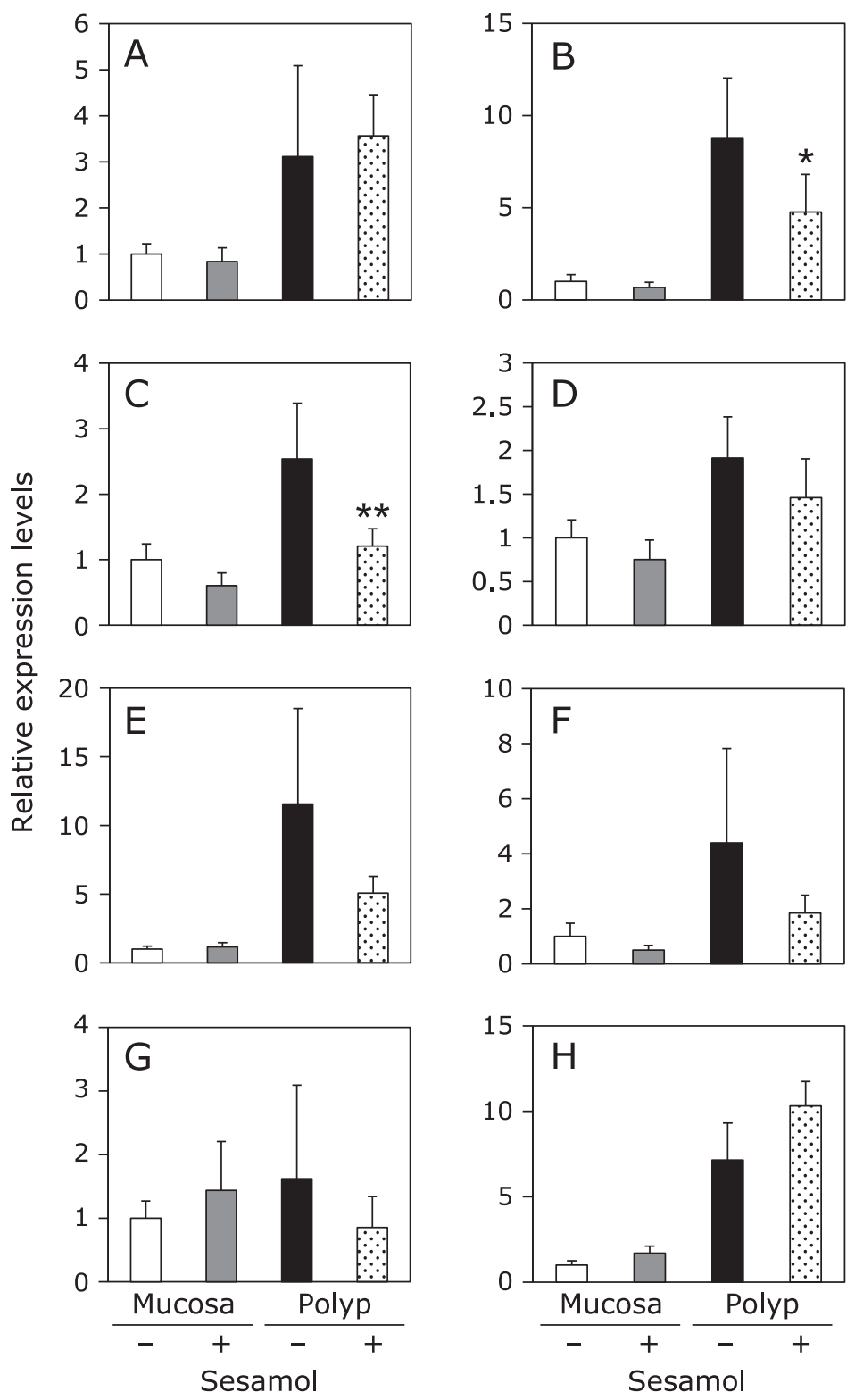

Fig. 4. Changes of inflammation-related factors in intestinal non-polyp mucosa parts and/or polyp parts of Min mice. Quantitative real-time PCR analysis were performed to determine COX-1 (A), COX-2 (B), cPGES (C), mPGES2 (D), EP1 (E), EP2 (F), EP3 (G), EP4 (H) mRNA expression levels in the polyps or non-polyp mucosa parts of Min mice, given diets containing sesamol at doses of 500 ppm for 8 weeks. Data are normalized with GAPDH expression level. Data are mean $\pm \mathrm{SD}, n=6 .{ }^{* *} p<0.01,{ }^{*} p<0.05$ vs $0 \mathrm{ppm}$.

EP1 and EP2 may additionally suppress tumor growth through a transmembrane $\mathrm{G}$ protein-coupled receptor.

In summary, sesamol suppressed the transcriptional activity of COX-2 gene in DLD-1 cells. Moreover, our in vivo data imply that agents that can suppress COX-2 expression at the gene level may be useful cancer chemopreventive agents. Further information of the mechanisms by which sesamol suppresses COX-2 expression may clarify the anti-inflammatory and anti-carcinogenetic properties of sesamol.

\section{Acknowledgments}

This work was supported by Grants-in-Aid for the Third-Term Comprehensive 10-Year Strategy for Cancer Control from the Ministry of Health, Labour, and Welfare of Japan, and also from Grants-in-Aid for Project Future, Relay for Life (Japan Cancer
Society), and also supported by the National Cancer Center Research Core Facility.

\section{Abbreviations}

cPGES cytosolic PGES

COX cyclooxygenase

FBS fetal bovine serum

mPGES microsomal PGES

MTT 3-(4,5-dimethylthiazol-2-yl)-2,5-diphenyltetrazolium bromide

$\mathrm{NF}-\kappa \mathrm{B} \quad$ nuclear factor $-\kappa \mathrm{B}$

ONPG $o$-nitrophenyl- $\beta$-D-galactopyranoside

PGs prostaglandins

PGES prostaglandin E synthase

PTKs protein-tyrosine kinases 

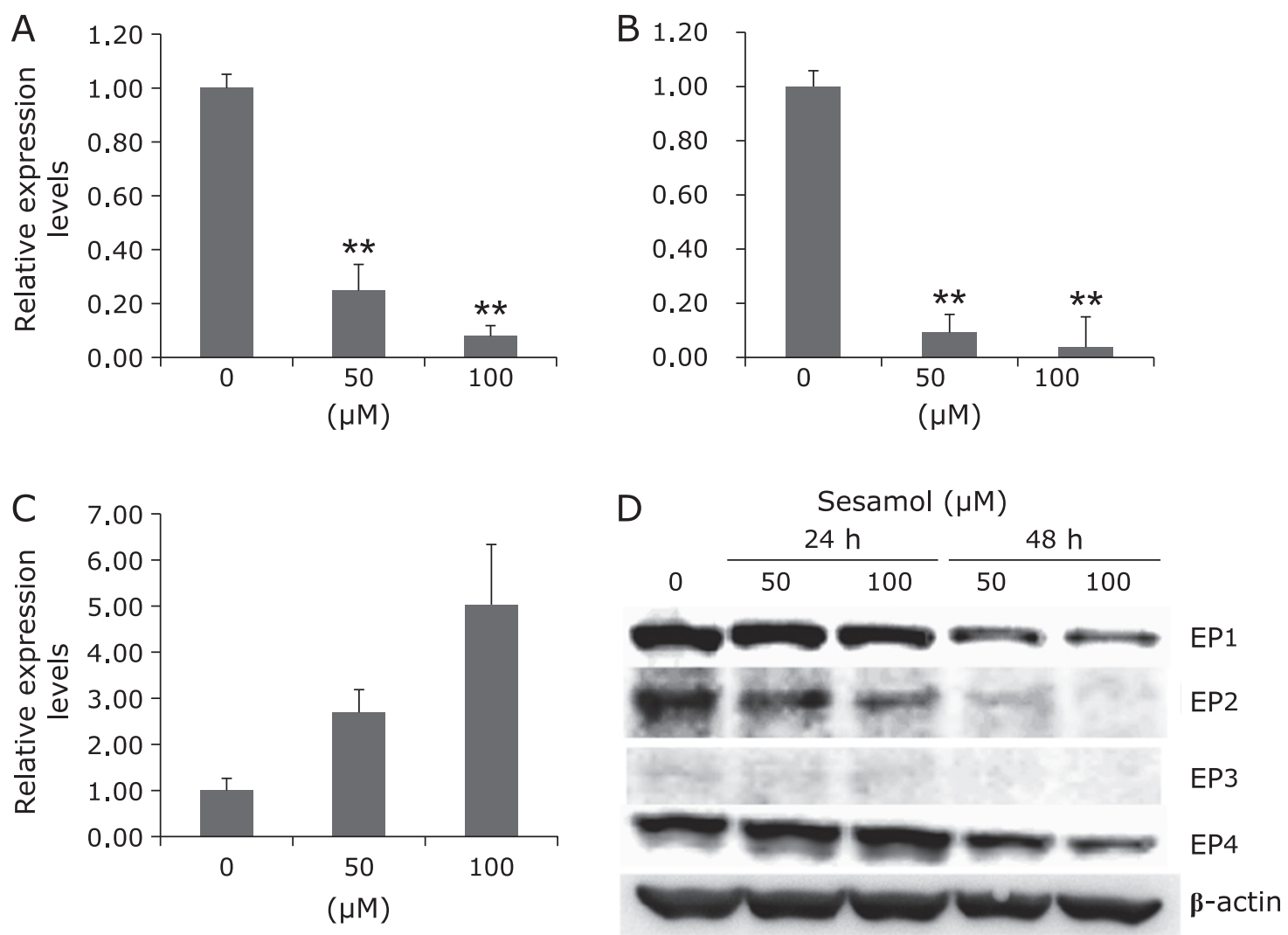

Fig. 5. Prostaglandin $E_{2}$ receptor expression in human colorectal cancer cells with or without sesamol treatment. DLD-1/COX-2-B2- $\beta$-gal-BSD cells were seeded in 6-well multiwell plates at a density of $2 \times 10^{6}$ cell/well and cultured in medium containing 50 and $100 \mu \mathrm{M}$ sesamol for $48 \mathrm{~h}$. After $48 \mathrm{~h}$ treatment, quantitative real-time PCR analysis was performed to determine EP1(A), EP2(B), EP4(C) mRNA levels. Data are normalized with GAPDH, Data are mean $\pm S D, n=3 . * * p<0.001$ vs 0 ppm. (D) EP1-4 protein was detected by western blot analysis, using DLD-1/COX-2-B2- $\beta$-gal-BSD cells (24-well plates at a density of $2 \times 10^{5}$ cell/well) with treatment of 50 and $100 \mu \mathrm{M}$ sesamol for 24 and $48 \mathrm{~h}$.

\section{Conflict of Interest}

No potential conflicts of interest were disclosed.

\section{References}

1 Sugano M, Akimoto K. Sesamin: a multifunctional gift from nature. J Chin Nutr Soc 1993; 18: 1-11.

2 Hagiwara A, Kokubo Y, Takesada Y, et al. Inhibitory effects of phenolic compounds on development of naturally occurring preneoplastic hepatocytic foci in long-term feeding studies using male F344 rats. Teratog Carcinog Mutagen 1996; 16: 317-325.

3 Hirose N, Doi F, Ueki T, et al. Suppressive effect of sesamin against 7,12dimethylbenz[a]-anthracene induced rat mammary carcinogenesis. Anticancer Res 1992; 12: 1259-1265.

4 Salerno JW, Smith DE. The use of sesame oil and other vegetable oils in the inhibition of human colon cancer growth in vitro. Anticancer Res 1991; 11: 209-215.

5 Minamiyama Y, Yoshikawa T, Tanigawa T, et al. Antioxidative effects of a processed grain food. J Nutr Sci Vitaminol (Tokyo) 1994; 40: 467-477.

6 Uchida M, Nakajin S, Toyoshima S, Shinoda M. Antioxidative effect of sesamol and related compounds on lipid peroxidation. Biol Pharm Bull 1996; 19: 623-626.

7 Kaur IP, Saini A. Sesamol exhibits antimutagenic activity against oxygen species mediated mutagenicity. Mutat Res 2000; 470: 71-76.

8 Mutoh M, Takahashi M, Wakabayashi K. Roles of prostanoids in colon carcinogenesis and their potential targeting for cancer chemoprevention. Curr Pharm Des 2006; 12: 2375-2382.

9 Oshima M, Dinchuk JE, Kargman SL, et al. Suppression of intestinal polyposis in $A p c^{\text {deta7116 }}$ knockout mice by inhibition of cyclooxygenase 2 (COX-2). Cell 1996; 87: 803-809.
10 Mutoh M, Takahashi M, Fukuda K, et al. Suppression by flavonoids of cyclooxygenase- 2 promoter-dependent transcriptional activity in colon cancer cells: structure-activity relationship. Jpn J Cancer Res 2000; 91: 686-691.

11 Mutoh M, Takahashi M, Fukuda K, et al. Suppression of cyclooxygenase-2 promoter-dependent transcriptional activity in colon cancer cells by chemopreventive agents with a resorcin-type structure. Carcinogenesis 2000; 21: 959-963.

12 Sasahara Y, Mutoh M, Takahashi M, et al. Suppression of promoterdependent transcriptional activity of inducible nitric oxide synthase by sodium butyrate in colon cancer cells. Cancer Lett 2002; 177: 155-161.

13 Fukuda K, Hibiya Y, Mutoh M, Koshiji M, Akao S, Fujiwara H. Inhibition by berberine of cyclooxygenase-2 transcriptional activity in human colon cancer cells. J Ethnopharmacol 1999; 66: 227-233.

14 Akarasereenont $\mathrm{P}$, Thiemermann C. The induction of cyclo-oxygenase-2 in human pulmonary epithelial cell culture (A549) activated by IL-1beta is inhibited by tyrosine kinase inhibitors. Biochem Biophys Res Commun 1996; 220: $181-185$.

15 Paul A, Pendreigh RH, Plevin R. Protein kinase $\mathrm{C}$ and tyrosine kinase pathways regulate lipopolysaccharide-induced nitric oxide synthase activity in RAW 264.7 murine macrophages. Br J Pharmacol 1995; 114: 482-488.

16 Niho N, Mutoh M, Komiya M, Ohta T, Sugimura T, Wakabayashi $\mathrm{K}$. Improvement of hyperlipidemia by indomethacin in Min mice. Int $J$ Cancer 2007; 121: 1665-1669.

17 Nakatsugi S, Fukutake M, Takahashi M, et al. Suppression of intestinal polyp development by nimesulide, a selective cyclooxygenase-2 inhibitor, in 
Min mice. Jpn J Cancer Res 1997; 88: 1117-1120.

18 Niho N, Mutoh M, Takahashi M, Tsutsumi K, Sugimura T, Wakabayashi $\mathrm{K}$. Concurrent suppression of hyperlipidemia and intestinal polyp formation by NO-1886, increasing lipiprotein lipase activity in Min mice. Proc Natl Acad Sci U S A 2005; 102: 2970-2974.

19 Niho N, Takahashi M, Shoji Y, et al. Dose-dependent suppression of hyperlipidemia and intestinal polyp formation in Min mice by pioglitazone, a PPAR gamma ligand. Cancer Sci 2003; 94: 960-964.

20 Shoji Y, Takahashi M, Kitamura T, et al. Downregulation of prostaglandin E receptor subtype EP3 during colon cancer development. Gut 2004; 53: 11511158.

21 Watanabe K, Kawamori T, Nakatsugi S, et al. Role of the prostaglandin E receptor subtype EP1 in colon carcinogenesis. Cancer Res 1999; 59: 50935096.

22 Mutoh M, Watanabe K, Kitamura T, et al. Involvement of prostaglandin E receptor subtype EP4 in colon carcinogenesis. Cancer Res 2002; 62: 28-32.

23 Sonoshita M, Takaku K, Sasaki N, et al. Acceleration of intestinal polyposis through prostaglandin receptor EP2 in $A p c^{\Delta 716}$ knockout mice. Nat Med 2001; 7: 1048-1051.

24 Coleman RA, Smith WL, Narumiya S. International Union of Pharmacology classification of prostanoid receptors: properties, distribution, and structure of the receptors and their subtypes. Pharmacol Rev 1994; 46: 205-229.

25 Ushikubi F, Hirata M, Narumiya S. Molecular biology of prostanoid receptors; an overview. J Lipid Mediat Cell Signal 1995; 12: 343-359. 